\section{Behavioral thermoregulation in the spectacled caiman (Caiman sclerops)}

\author{
STEVEN J. LINTON \\ Wichita State University, Wichita, Kansas 67208
}

This report describes an operant conditioning technique for studying crocodilians. As experimental subjects, crocodilians present some special problems. For example, their size limits direct handling. Further, because they may go for prolonged periods without eating, food probably is not an effective reinforcer. And, because of the crocodilian's limited overt activity, obtaining a specified response can be very difficult; much of the time crocodilians seldom move. In addition, their ability to manipulate objects is limited by their morphology. Therefore, responses (e.g., barpresses) and procedures (e.g., shaping) typically used in such experiments are not practical.

Weiss and Laties (1961) demonstrated behavioral thermoregulation in the rat by having the animals press a bar to activate a heat lamp. Crocodilians are cold blooded, so it was assumed that heat might serve as a reinforcing stimulus and that crocodilians would demonstrate behavioral thermoregulation. Because it appeared to be difficult for the reptile to move its head forward to depress a key (as pigeons do), the behavior to be conditioned was simply making contact with a metal plate.

\section{METHOD}

\section{Subject and Apparatus}

An adult male spectacled caiman (Caiman sclerops) about $4 \mathrm{ft}$ long served as the subject. The animal was fed mice until satiated once per week.

The caiman was housed in a screen cage constructed of a wood frame with a wire mesh attached. The floor was made of Masonite. At one end of the cage was a plastic water pan, enabling the subject to immerse itself. At the opposite end, a metal plate $(10.16 \times 15.24 \mathrm{~cm})$ was placed in the corner and a wire screen was placed on the floor so that the animal would make contact with the screen whenever in the vicinity of the plate. A drinkometer circuit was connected to the screen floor and the metal plate so that touching the plate would complete a circuit; each contact was recorded as one response. An infrared heat lamp $(250 \mathrm{~W})$ was located about $.6 \mathrm{~m}$ above the screen floor. The contingencies were administered via a BRS $\mathbf{3 0 0}$ series solid state unit and appropriate electromechanical devices. Data were recorded with a counter, cumulative recorder, and occasional observation.

The author expresses appreciation to Dr. Gary Greenberg for his scholarly assistance in preparing this paper, and to Delphi Messinger, and Dr. Donald Distler for assistance in obtaining and maintaining the subject.

\section{Procedure}

The room temperature was lowered to $20^{\circ} \mathrm{C}$ during the night throughout the experiment. On Day 1 the subject was placed in the vicinity of the heat lamp, and several noncontingent reinforcements consisting of 10 -sec activations of the heat lamp were presented during the course of an hour. For the next hour, the opportunity to respond was maintained with every response being reinforced.

Fixed-ratio (FR) schedules were employed throughout. The ratio requirements were gradually increased from continuous reinforcement to an FR 4. The caiman had free access to respond and was on 10-12 h/day, 7 days/week.

\section{RESULTS}

The caiman began responding on the first session immediately after the noncontingent exposure to the heat lamp was terminated. The response was conditioned without proding the subject or gradually shaping it and the response was maintained for the duration of the experiment. Figure 1 shows the cumulative record for the FR 4 contingency. Section A of the figure shows responding followed by a postreinforcement pause. Section B shows typical FR responding and reveals a consistent pattern of responding and obtaining several reinforcements, followed by nonresponding for several minutes. The subject developed a similar daily cycle of periods of responding followed by long periods (up to a few hours) of nonresponding. The subject exhibited tremendous control of response movements. The subject's snout would often move just enough to make contact with the plate. Thus, observing the subject respond was similar to watching the minute hand of a clock; one knows that it is moving, but cannot perceive the movement itself.

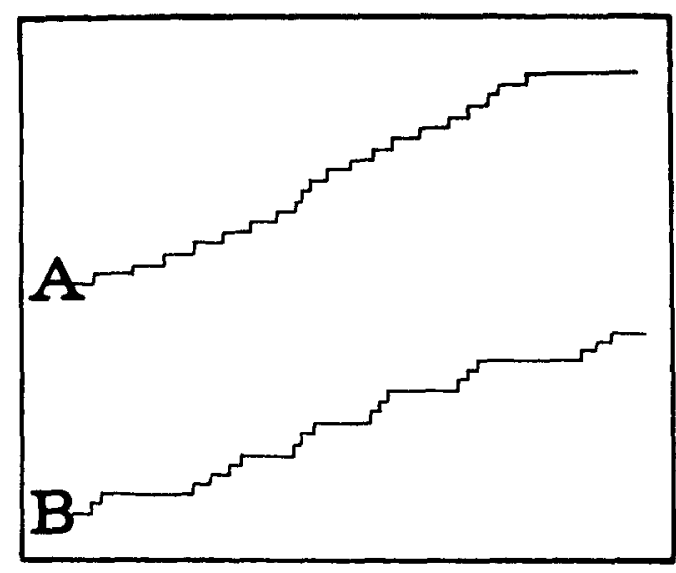

Figure 1. Caiman performance under the FR 4 schedule. Note the responding followed by short pauses in Section $\mathbf{A}$, and also the longer pauses which follow several reinforcements in Section $B$. 


\section{DISCUSSION}

This study successfully developed behavioral thermoregulation in a spectacled caiman. Autoshaping, which was not anticipated, bypassed problems with shaping a response. And, the use of heat as a reinforcer was effective and easy to administer.

This paradigm seems quite adaptable for zoo exhibits as well as research with crocodilians. Such an exhibit is being planned for a local zoo.

\section{REFERENCE}

Weiss, Bernard, \& Laties, Victor G. Behavioral thermoregulation. Science, 1961, 133, 1338-1344. 